\title{
Parameters of liver function in patients with psoriasis vulgaris
}

\author{
Wskaźniki wydolności wątroby u pacjentów z łuszczycą
}

Magdalena Oszukowska, Magdalena Kręgiel, Barbara Kaczmarek, Andrzej Kaszuba

Department of Dermatology, Pediatric and Oncological Dermatology, Medical University of Lodz, Poland

Klinika Dermatologii, Dermatologii Dziecięcej i Onkologicznej Uniwersytetu Medycznego w Łodzi, Polska

Dermatol Rev/Przegl Dermatol 2017, 104, 529-543

DOI: https://doi.org/l0.51/4/dr.2017.71218

\author{
CORRESPONDING AUTHOR/ \\ ADRES DO KORESPONDENCJI: \\ prof. Andrzej Kaszuba MD, PhD \\ Klinika Dermatologii, \\ Dermatologii Dziecięcej \\ i Onkologicznej \\ Uniwersytet Medyczny w Łodzi \\ ul. Kniaziewicza 1/5 \\ 91-347 Łódź, Polska \\ tel.: +48 426511072 \\ e-mail: andrzej.kaszuba@umed. \\ lodz.pl
}

\begin{abstract}
Introduction. Patients with psoriasis develop nonalcoholic fatty liver disease more often than healthy subjects.

Objective. To estimate the level of basic parameters of liver function, compare these values between groups of patients with psoriasis and healthy individuals, and refer these values to selected risk factors of developing atherosclerosis.

Material and methods. A case-control study in the dermatology department included 66 patients with psoriasis and 30 healthy volunteers. The two groups were comparable as regards age, sex and body mass index as well as abdominal circumference. In all subjects we estimated the parameters of liver function and selected the risk factors of atherosclerosis.

Results. $\gamma$-Glutamyltransferase activity in patients with psoriasis was significantly higher than in the reference group individuals $(p=0.002)$ and it applies to men only $(p=0.0003)$. In women $\gamma$-glutamyltransferase activity was higher in patients with positive family history of psoriasis $(p=0.03)$. $\gamma$-Glutamyltransferase activity was also higher in smoking patients $(p=0.02)$. Activity and concentration of other liver function markers (alanine aminotransferase, aspartate aminotransferase, and bilirubin) did not differ significantly between healthy individuals and patients with psoriasis. There were no differences between patients with severe, moderate and mild psoriasis. A negative correlation between bilirubin concentration and age of patients $(p=$ $0.02)$ and bilirubin and C-reactive protein concentration $(p=0.03)$ was observed. Activity of alanine aminotransferase correlated positively with abdominal circumference $(p=0.001)$, uric acid concentration $(p=0.004)$ and body mass index $(p=0.001)$. Activity of aspartate aminotransferase correlated positively with abdominal circumference $(p=0.001)$, uric acid concentration $(p=0.03)$ and body mass index $(p=$ 0.001 ). Additionally, the increase in alanine aminotransferase activity was proportional to the increase in cholesterol $(p=0.01)$ and apolipoprotein B concentrations $(p=0.03)$. $\gamma$-Glutamyltransferase activity correlated positively with the concentration of uric acid $(p=0.008)$, cholesterol $(p=0.04)$, triglycerides $(p=0.04)$, and apolipoprotein B $(p=0.03)$.

Conclusions. In patients with psoriasis increased activity of alanine aminotransferase and aspartate aminotransferase parameters probably result from liver diseases since they accompany dyslipidemia and obesity whereas the increase of $\gamma$-glutamyltransferase activity is probably associated mainly with psoriasis.
\end{abstract}




\section{STRESZCZENIE}

Wprowadzenie. U pacjentów chorujących na łuszczycę częściej obserwuje się niealkoholowe stłuszczenie wątroby niż u osób zdrowych.

Cel pracy. Ocena wartości podstawowych wykładników biochemicznych wydolności wątroby, porównanie pomiędzy grupą chorych na łuszczycę i osób zdrowych, jak również odniesienie tych wartości do wybranych czynników ryzyka wystąpienia miażdżycy.

Materiał i metody. Badanie kliniczno-kontrolne obejmowało 66 osób z rozpoznaną łuszczyca hospitalizowanych w Klinice Dermatologii i 30 zdrowych ochotników. Obie grupy były zbliżone do siebie pod względem wieku, płci, wskaźnika masy ciała oraz obwodu brzucha. U osób badanych oznaczono parametry wydolności wątroby i wybrane czynniki ryzyka rozwoju miażdżycy.

Wyniki. Aktywność $\gamma$-glutamylotransferazy u chorych na łuszczycę była znamiennie większa niż $\mathrm{u}$ osób $\mathrm{z}$ grupy kontrolnej $(p=0,002)$, co dotyczyło tylko mężczyzn $(p=0,0003)$. Wśród kobiet $\mathrm{z}$ łuszczycą aktywność $\gamma$-glutamylotransferazy była wyższa $\mathrm{u}$ tych $\mathrm{z}$ dodatnim wywiadem rodzinnym w kierunku łuszczycy $(p=0,03)$. Aktywność $\gamma$-glutamylotransferazy była także większa u pacjentów palących papierosy $(p=0,02)$. Stężenie i aktywność innych wskaźników wydolności wątroby (aminotransferazy alaninowej, aminotransferazy asparaginianowej i bilirubiny) nie różniły się znacząco między osobami zdrowymi i chorymi na łuszczycę. Nie stwierdzono żadnych różnic między pacjentami z ciężką, umiarkowaną i łagodną postacią choroby. Wykazano ujemną korelację między stężeniem bilirubiny i wiekiem pacjentów $(p=0,02)$ oraz stężeniem białka C-reaktywnego $(p=0,03)$. Aktywność aminotransferazy alaninowej pozytywnie korelowała $\mathrm{z}$ obwodem brzucha $(p=0,001)$, stężeniem kwasu moczowego $(p=0,004)$ i wskaźnikiem masy ciała $(p=0,001)$. Aktywność aminotransferazy asparaginianowej pozytywnie korelowała z obwodem brzucha $(p=0,001)$, stężeniem kwasu moczowego $(p=0,03)$ i wskaźnikiem masy ciała $(p=$ $0,001)$. Ponadto zwiększona aktywność aminotransferazy alaninowej była proporcjonalna do wzrostu stężenia cholesterolu $(p=0,01)$ i apolipoproteiny B $(p=0,03)$. Aktywność $\gamma$-glutamylotransferazy korelowała pozytywnie ze stężeniem kwasu moczowego $(p=0,008)$, cholesterolu $(p=0,04)$, trójglicerydów $(p=0,04)$ i apolipoproteiny B $(p=0,03)$.

Wnioski. U chorych na łuszczycę wzrost aktywności aminotransferazy alaninowej i asparaginianowej wynika prawdopodobnie $\mathrm{z}$ towarzyszącej dyslipidemii i otyłości, natomiast do wzrostu aktywności $\gamma$-glutamylotransferazy przyczynia się łuszczyca.

Key words: non-alcoholic fatty liver diseases, alanine aminotransferase, aspartate aminotransferase, $\gamma$-glutamyltransferase, bilirubin, psoriasis.

Słowa kluczowe: niealkoholowe stłuszczenie wątroby, aminotransferaza alaninowa, aminotransferaza asparaginianowa, $\gamma$-glutamylotransferaza, bilirubina, łuszczyca.

\section{INTRODUCTION}

Psoriasis is a chronic, immune-mediated inflammatory disease, affecting 2\% of the European population. Psoriasis is characterized by hyperproliferation of keratinocytes and dermal infiltration by activated $\mathrm{T}$ cells, neutrophils, and dendritic cells. The main

\section{WPROWADZENIE}

Łuszczyca jest przewlekłą chorobą zapalną o podłożu immunologicznym, występującą u $2 \%$ populacji europejskiej. Choroba charakteryzuje się hiperproliferacją keratynocytów oraz obecnością w skórze nacieku zapalnego złożonego z aktywowanych limfocytów $\mathrm{T}$, 
manifestation of disease is skin involvement characterized by erythematous plaques.

The connections between psoriasis and other medical conditions such as hypertension, glucose intolerance, obesity, dyslipidemia, cardiovascular diseases, depression, non-alcoholic fatty liver disease (NAFLD), inflammatory bowel diseases and lymphomas are widely described in the literature [1].

Nonalcoholic fatty liver disease is one of the most common pathologies affecting the organ and occurs in $30 \%$ of the adult population in developed countries. Nonalcoholic fatty liver disease is characterized by presence of hepatic steatosis confirmed by imaging or histopathology tests with no secondary causes of fat accumulation within the liver (among others alcoholism/medications). Nonalcoholic fatty liver disease is associated with occurrence of metabolic syndrome which, similarly to NAFLD, has its grounds in insulin resistance. Based on the histopathology image, two main types of NAFLD may be distinguished:

- non-alcoholic steatohepatitis (NASH) - hepatic steatosis with ballooning degeneration of hepatocytes, with or without fibrosis;

- non-alcoholic fatty liver (NAFL) - hepatic steatosis with no features of hepatocyte damage [2].

The causes of psoriasis and NAFLD coexistence are not fully explained. Both diseases are strongly associated with metabolic syndrome. It is known that they have many common inflammatory mechanisms related to both genetic and environmental factors. It seems that some cytokines, such as interleukin 6 (IL-6), IL-17, and tumor necrosis factor $\alpha$ (TNF- $\alpha$ ), which are produced in excess in the skin of patients with psoriasis, contribute to the development of insulin resistance, which promotes NAFLD [3].

\section{OBJECTIVE}

The purpose of this study was to estimate the activity or concentration of basic parameters of liver function, compare values in groups of patients with psoriasis versus healthy individuals, and refer these values to the selected risk factors of developing atherosclerosis.

\section{MATERIAL AND METHODS}

The case-control study was conducted in 96 persons, including 47 womens and 49 mans. The sample group included 66 patients (31 womens and 35 mans) with clinically diagnosed psoriasis vulgaris, aged between 21 and 73 years, hospitalized in 20142015 in the Dermatology Department in Lodz. The reference group included 30 clinically healthy individuals (16 womens and 14 mans), aged between neutrofilów oraz komórek dendrytycznych. Głównym objawem łuszczycy są wykwity grudkowe, zlewające się w blaszki.

W piśmiennictwie szeroko opisuje się zależności między łuszczycą a innymi chorobami, takimi jak nadciśnienie, nietolerancja glukozy, otyłość, dyslipidemia, choroby układu krążenia, depresja, niealkoholowa stłuszczeniowa choroba wątroby (non-alcoholic fatty liver disease - NAFLD), nieswoiste zapalenia jelit oraz chłoniaki [1].

Niealkoholowa stłuszczeniowa choroba wątroby jest jednym z najczęstszych schorzeń tego narządu. Występuje u 30\% dorosłych w krajach rozwiniętych. Charakteryzuje się obecnością cech stłuszczenia wątroby w badaniach obrazowych lub histopatologicznych przy braku innych przyczyn odkładania się tłuszczu w tym narządzie (np. uszkodzenie przez alkohol/leki). Niealkoholowa stłuszczeniowa choroba wątroby wiąże się z zespołem metabolicznym, którego podłożem, podobnie jak NAFLD, jest insulinooporność. Na podstawie obrazu histopatologicznego NAFLD można podzielić na dwa podstawowe typy: - niealkoholowe stłuszczeniowe zapalenie wątroby (non-alcoholic steatohepatitis - NASH) - stłuszczenie z cechami zwyrodnienia balonowatego hepatocytów z towarzyszącym włóknieniem lub bez włóknienia; - niealkoholowe stłuszczenie wątroby (non-alcoholic fatty liver - NAFL) - stłuszczenie wątroby bez cech uszkodzenia hepatocytów [2].

Przyczyny współwystępowania łuszczycy i NAFDL nie zostały jednoznacznie poznane. Obie choroby wykazują silną zależność z zespołem metabolicznym. Potwierdzono, że mają wiele wspólnych mechanizmów zapalnych związanych z czynnikami genetycznymi i środowiskowymi. Przypuszcza się, że niektóre cytokiny, takie jak interleukina 6 (IL-6) i IL-17, czynnik martwicy nowotworów $\alpha$ (tumor necrosis factor $\alpha-\mathrm{TNF}-\alpha$ ), wytwarzane w nadmiarze w skórze pacjentów z łuszczycą przyczyniają się do wystąpienia insulinooporności, co z kolei sprzyja rozwojowi NAFLD [3].

\section{CEL PRACY}

Celem pracy była ocena podstawowych biochemicznych wskaźników wydolności wątroby oraz porównanie ich stężeń u chorych na łuszczycę i osób zdrowych, a także odniesienie uzyskanych wartości do wybranych czynników ryzyka rozwoju miażdżycy.

\section{MATERIAŁ I METODY}

Badanie kliniczno-kontrolne obejmowało łącznie 96 osób, w tym 47 kobiet i 49 mężczyzn. Grupa badana liczyła 66 pacjentów (31 kobiet i 35 mężczyzn) z klinicznym rozpoznaniem łuszczycy zwykłej, w wieku od 21 do 73 lat, hospitalizowanych w Klinice Derma- 
30 and 70 years. The reference group was smaller than the sample group because the healthy individuals were to be compare with a subgroup of the patients with psoriasis depending of the severity of the pathological changes (according to the Psoriasis Area and Severity Index (PASI) score):

- patients with psoriasis with PASI score equal to or lower than 10 points (21 persons - 31.8\%);

- patients with psoriasis with PASI score higher than 10 points (45 persons $-68.2 \%$ ).

Both groups were comparable as regards age, sex and body mass index (BMI) as well as abdominal circumference (Table 1). Patients participating in the study were diagnosed with psoriasis based on clinical examination.

The study excluded patients with:

- symptoms of infections present on admission to the clinic (fever, sore throat, cough, dysuria symptoms),

- neoplastic diseases,

- chronic diseases of, among others, the liver, pancreas, infectious diseases, heart failure,

- abnormal results of TSH, fT3 or fT4 tests,

- megaloblastic anemia, and patients:

- taking medications affecting lipid metabolism, concentration of uric acid or homocysteine, including statin, treated with cyclosporin A, methotrexate, sulfasalazine and retinoids,

- abusing alcohol (drinking more than 10-12 g of ethanol a day, which contributes to the development of alcoholic liver disease)

- under the age of 18 years.

In the past some of the patients were treated with methotrexate, cyclosporin $\mathrm{A}$, and retinoids and re- tologii w Łodzi w latach 2014-2015. Grupa kontrolna obejmowała 30 klinicznie zdrowych osób (16 kobiet i 14 mężczyzn) w wieku od 30 do 70 lat. Grupa kontrolna była mniej liczna od grupy badanej, ponieważ założono porównanie zdrowych ochotników z częścią pacjentów chorujących na łuszczycę w zależności od nasilenia zmian chorobowych (na podstawie wyników w skali PASI - Psoriasis Area and Severity Index):

- pacjenci z łuszczycą z wartością PASI równą lub niższą niż 10 punktów (21 osób - 31,8\%),

- pacjenci z łuszczycą z wartością PASI wyższą niż 10 punktów (45 osób - 68,2\%).

Obie grupy były zbliżone pod względem wieku, płci, wskaźnika masy ciała (body mass index - BMI) oraz obwodu brzucha (tab. 1). Rozpoznanie łuszczycy u pacjentów uczestniczących w badaniu było oparte na obrazie klinicznym.

$\mathrm{Z}$ badania wyłączono chorych $\mathrm{z}$ :

- objawami zakażenia (gorączką, bólem gardła, kaszlem, objawami dyzurycznymi) przy przyjęciu do Kliniki,

- chorobami nowotworowymi,

- chorobami przewlekłymi, m.in. wątroby, trzustki, chorobami zakaźnymi, niewydolnością serca,

- nieprawidłowymi stężeniami TSH, fT3 lub fT4,

- niedokrwistością megaloblastyczną, jak również pacjentów:

- przyjmujących leki wpływające na metabolizm tłuszczów, stężenie kwasu moczowego lub homocysteiny, m.in. statyny, a także leczonych cyklosporyną A, metotreksatem, sulfasalazyną i retinoidami,

- nadużywających alkoholu (tj. spożywających ponad 10-12 g etanolu dziennie, co przyczynia się do rozwoju alkoholowej choroby wątroby),

- poniżej 18. roku życia.

Table I. Comparison of basic parameters between study and reference group

Tabela I. Porównanie podstawowych parametrów między badanymi grupami

\begin{tabular}{|c|c|c|c|c|c|c|c|c|c|c|c|c|}
\hline \multirow{2}{*}{$\begin{array}{l}\text { Parameter/ } \\
\text { Parametr }\end{array}$} & \multirow[t]{2}{*}{ Sex/Płeć } & \multicolumn{5}{|c|}{ Study group/Grupa badana } & \multicolumn{5}{|c|}{ Reference group/Grupa kontrolna } & \multirow[t]{2}{*}{$P$} \\
\hline & & $N$ & Min.-max. & $\overline{\bar{x}}$ & SD/OS & $\mathrm{Me}$ & $N$ & Min.-max. & $\overline{\bar{x}}$ & SD/OS & $\mathrm{Me}$ & \\
\hline \multirow{3}{*}{ age/wiek } & $\mathrm{W} / \mathrm{K}$ & 31 & $21-73$ & 53.7 & 12.9 & 55 & 16 & $30-70$ & 51.7 & 13.5 & 54 & $>0.05$ \\
\hline & M & 35 & $28-69$ & 45.2 & 11.3 & 42 & 14 & $30-65$ & 44.2 & 13.9 & 37 & $>0.05$ \\
\hline & $\begin{array}{c}W+M / \\
K+M\end{array}$ & 66 & $21-73$ & 49.2 & 12.7 & 50 & 30 & $30-70$ & 48.2 & 13.9 & 49 & $>0.05$ \\
\hline \multirow{3}{*}{ BMI } & $\mathrm{W} / \mathrm{K}$ & 31 & 19.4-36.1 & 27.2 & 4.63 & 30.9 & 16 & 19.7-47 & 31 & 5.4 & 27.7 & $>0.05$ \\
\hline & M & 35 & $23.9-36.8$ & 28.6 & 2.93 & 27.5 & 14 & $20-41.9$ & 28.4 & 5 & 28.4 & $<0.05$ \\
\hline & $\begin{array}{c}W+M / \\
K+M\end{array}$ & 66 & 19.7-47.8 & 29.6 & 5.3 & 29 & 30 & 19.4-36.8 & 27.9 & 3.9 & 28 & $>0.05$ \\
\hline \multirow{3}{*}{$\begin{array}{l}\text { abdominal } \\
\text { circumference/ } \\
\text { obwód brzucha }\end{array}$} & $\mathrm{W} / \mathrm{K}$ & 31 & $67-130$ & 96.5 & 17.4 & 91 & 16 & $70-120$ & 96.6 & 13.3 & 97.5 & $>0.05$ \\
\hline & $M$ & 35 & $69-127$ & 95.8 & 13 & 94 & 14 & $88-128$ & 99.7 & 9.5 & 98 & $>0.05$ \\
\hline & $\begin{array}{c}W+M / \\
K+M\end{array}$ & 66 & $67-130$ & 96.1 & 15.1 & 92.5 & 30 & $70-128$ & 98 & 11.6 & 98 & $>0.05$ \\
\hline
\end{tabular}

$N$ - number of persons, $W$ - women, $M$ - men, $\bar{x}$ - mean, SD - standard deviation, Me - median, BMI - body mass index.

$N$ - liczba osób, K - kobiety, M - mężczyźni, $\bar{x}$ - średnia, OS - odchylenie standardowe, Me - mediana, BMl - wskaźnik masy ciała. 
ceived PUVA therapy, but they ceased applying these treatment methods at least 3 months preceding the trial.

Table 2 presents detailed data of the patients suffering from the disease.

The trial was conducted under the approval of the Bioethical Committee of the Medical University of Lodz. All participants of the trial were aware of its subject matter and gave their voluntary consent to participate in it.

A detailed history on the course of psoriasis was taken from each patient and included the following information: age of the patient, duration of the disease, frequency of relapses, location of skin lesions, family history, pruritus exacerbation. Moreover, the questionnaire included information on coexisting diseases, medications taken, tobacco use, alcohol drinking habits and diet applied.

A detailed medical history, related to previous diseases and illnesses and hereditary factors, was also taken from healthy individuals included in the control group.

All trial participants underwent a detailed physical examination (including assessment of their body mass, height, BMI and abdominal circumference) and dermatological examination.
Niektórzy pacjenci byli w przeszłości leczeni metotreksatem, cyklosporyną A i retinoidami, a także PUVA, jednak zakończyli terapię co najmniej 3 miesiące przed rozpoczęciem badania.

Szczegółowe dane chorych zestawiono w tabeli 2.

Na przeprowadzenie badania uzyskano zgodę Komisji Bioetycznej przy Uniwersytecie Medycznym w Łodzi. Wszyscy uczestnicy zostali poinformowani o celu badania i wyrazili dobrowolną zgodę na udział.

Od każdego z pacjentów zebrano szczegółowy wywiad obejmujący: wiek, czas trwania choroby, częstość nawrotów, lokalizację zmian skórnych, obciążenia rodzinne i nasilenie świądu. W kwestionariuszu uwzględniono także informacje o chorobach współistniejących, przyjmowanych lekach, paleniu tytoniu, spożywaniu alkoholu oraz diecie.

Szczegółowy wywiad lekarski obejmujący przebyte choroby oraz wywiad rodzinny zebrano również od zdrowych ochotników z grupy kontrolnej.

U wszystkich uczestników badania przeprowadzono szczegółowe badanie fizykalne (masa ciała, wzrost, BMI oraz obwód brzucha), a także badanie dermatologiczne.

Od pacjentów zakwalifikowanych do badania pobrano na czczo, między godziną 7.00 a 8.00 rano,

Table 2. Characteristics of study group

Tabela 2. Charakterystyka badanej grupy

\begin{tabular}{|c|c|c|c|c|c|c|c|c|c|c|}
\hline \multirow{2}{*}{\multicolumn{2}{|c|}{ Parameter/Parametr }} & \multirow[t]{2}{*}{$\mathrm{W} / \mathrm{K}$} & \multirow[t]{2}{*}{$M$} & \multirow{2}{*}{$\begin{array}{c}W+M / \\
K+M\end{array}$} & \multicolumn{3}{|c|}{ PASI $\leq 10$} & \multicolumn{3}{|c|}{ PASI $>10$} \\
\hline & & & & & W & $M$ & $\begin{array}{c}W+M / \\
K+M\end{array}$ & $\mathrm{~W} / \mathrm{K}$ & $M$ & $\begin{array}{l}W+M \\
K+M\end{array}$ \\
\hline \multicolumn{2}{|c|}{ number of patients/iczba pacjentów } & 31 & 35 & 66 & 9 & 12 & 21 & 22 & 23 & 45 \\
\hline \multicolumn{2}{|c|}{$\begin{array}{l}\text { positive family history of psoriasis/ } \\
\text { dodatni wywiad rodzinny } \\
\text { w kierunku łuszczycy }\end{array}$} & 17 & 19 & 36 & 6 & 5 & 11 & 11 & 14 & 25 \\
\hline \multirow{5}{*}{$\begin{array}{l}\text { duration } \\
\text { of psoriasis } \\
\text { [years]/ } \\
\text { czas trwania } \\
\text { łuszczycy } \\
\text { [lata] }\end{array}$} & $\leq 5$ & 8 & 8 & 16 & 2 & 5 & 7 & 6 & 3 & 9 \\
\hline & $\begin{array}{l}>5 \text { and } \leq 10 / \\
>5 i \leq 10\end{array}$ & 3 & 5 & 8 & । & 2 & 3 & 2 & 3 & 5 \\
\hline & $\begin{array}{l}>10 \text { and } \leq 20 / \\
>10 i \leq 20\end{array}$ & 7 & 3 & 10 & 4 & 0 & 4 & 3 & 3 & 6 \\
\hline & $\begin{array}{l}>20 \text { and } \leq 30 / \\
>20 i \leq 30\end{array}$ & 7 & 14 & 21 & I & 4 & 5 & 6 & 10 & 16 \\
\hline & $>30$ & 6 & 5 & 11 & I & 1 & 2 & 5 & 4 & 9 \\
\hline \multicolumn{2}{|c|}{$\begin{array}{l}\text { metabolic syndrome/ } \\
\text { zespół metaboliczny }\end{array}$} & 16 & 9 & 25 & 5 & 3 & 8 & 11 & 6 & 17 \\
\hline \multicolumn{2}{|c|}{$\begin{array}{l}\text { smoking habit/ } \\
\text { nałogowe palenie tytoniu }\end{array}$} & 9 & 21 & 30 & 2 & 7 & 9 & 7 & 14 & 21 \\
\hline \multicolumn{2}{|c|}{$\begin{array}{l}\text { abnormal diet/ } \\
\text { niezbilansowana dieta }\end{array}$} & 16 & 25 & 41 & 7 & 5 & 12 & 10 & 18 & 28 \\
\hline \multicolumn{2}{|c|}{ diabetes/cukrzyca } & 0 & 0 & 0 & । & 0 & I & 3 & 0 & 3 \\
\hline
\end{tabular}

W-women, $M-$ men.

K- kobiety, M-mężczyźni. 
Venous blood samples were taken from fasting patients qualified for the trial between 7 and 8 a.m., in the amount of $8 \mathrm{ml}$ to a tube for blood clot and $4 \mathrm{ml}$ to a tube with EDTA at one time.

\section{Statistical analysis}

Statistical analyses were performed using the program Statistica 10 with the significance level set at $p<0.05$. Student's $t$-test, Mann-Whitney $U$ test and Spearman's rank correlation coefficient were applied. The results were expressed as the mean \pm standard deviation (SD).

\section{RESULTS}

The trials performed showed that $\gamma$-glutamyltransferase (GGT) activity in patients with psoriasis was significantly higher than in the reference group individuals $(p=0.02)$ and it applied to mans only $(p=$ 0.0003 ) (Table 3). The GGT activity was not influenced by severity of psoriasis (Table 4), occurrence of metabolic syndrome (Table 5) or dietary habits (Table 6). The GGT activity was higher in smoking patients $(p=0.02)$ (Table 7) and in womens with positive family history of psoriasis $(p=0.03$ ) (Table 8).

Level and activity of other liver function markers (alanine aminotransferase - ALT, aspartate ami- próbki krwi żylnej o objętości $8 \mathrm{ml}$ do probówki na skrzep oraz o objętości $4 \mathrm{ml}$ do probówki z EDTA.

\section{Analiza statystyczna}

Analizy statystyczne wykonano za pomocą programu Statistica 10. Za poziom istotności przyjęto wartość $p<0,05$. Zastosowano test $t$ Studenta, test U Manna-Whitneya oraz współczynnik korelacji rang Spearmana. Wyniki wyrażono w postaci średniej \pm odchylenie standardowe (standard deviation - SD).

\section{WYNIKI}

Badanie wykazało znamiennie wyższą aktywność $\gamma$-glutamylotransferazy (GGT) u pacjentów z łuszczycą niż u osób z grupy kontrolnej $(p=0,02)$, jednak wyłącznie u mężczyzn ( $p=0,0003)$ (tab. 3). Aktywność GGT nie była zależna od stopnia nasilenia łuszczycy (tab. 4), obecności zespołu metabolicznego (tab. 5) i nawyków żywieniowych (tab. 6). Stwierdzono, że aktywność GGT była wyższa u palaczy $(p=0,02)($ tab. 7) oraz $\mathrm{u}$ kobiet $\mathrm{z}$ dodatnim wywiadem rodzinnym w kierunku łuszczycy $(p=0,03)$ (tab. 8).

Pod względem stężenia i aktywności innych markerów czynności wątroby (aminotransferaza alaninowa - ALT, aminotransferaza asparaginianowa - AST, bilirubina) nie odnotowano znamiennych różnic

Table 3. Comparison of liver function parameters in study and reference group

Tabela 3. Porównanie parametrów wydolności wątroby między chorymi na łuszczycę i zdrowymi ochotnikami

\begin{tabular}{|c|c|c|c|c|c|c|c|c|c|c|c|c|}
\hline \multirow{2}{*}{$\begin{array}{l}\text { Parameter/ } \\
\text { Parametr }\end{array}$} & \multirow[t]{2}{*}{ Sex/Płeć } & \multicolumn{5}{|c|}{ Study group/Grupa badana } & \multicolumn{5}{|c|}{ Reference group/Grupa kontrolna } & \multirow[t]{2}{*}{$P$} \\
\hline & & $N$ & Min.-max. & $\overline{\bar{x}}$ & SD/OS & $\mathrm{Me}$ & $N$ & Min.-max. & $\overline{\bar{x}}$ & SD/OS & $\mathrm{Me}$ & \\
\hline \multirow{3}{*}{$\begin{array}{l}\text { bilirubin/bilirubina } \\
{[\mathrm{mg} / \mathrm{dl}]}\end{array}$} & $\mathrm{W} / \mathrm{K}$ & 31 & $0.3-1.2$ & 0.6 & 0.2 & 0.5 & 16 & $0.25-0.9$ & 0.5 & 0.2 & 0.5 & 0.7 \\
\hline & $M$ & 35 & $0.1-6.4$ & 0.8 & । & 0.7 & 14 & $0.5-1.5$ & 0.8 & 0.3 & 0.7 & 0.4 \\
\hline & $\begin{array}{c}W+M / \\
K+M\end{array}$ & 66 & $0.1-6.4$ & 0.7 & 0.8 & 6.4 & 30 & $0.3-1.5$ & 0.6 & 10.2 & 0.6 & 0.8 \\
\hline \multirow{3}{*}{$\mathrm{ALT}[\mathrm{U} / \mathrm{l}]$} & $\mathrm{W} / \mathrm{K}$ & 31 & $7-65$ & 24.3 & 14.3 & 22 & 16 & $9-76$ & 23.5 & 16.5 & 19.5 & 0.6 \\
\hline & M & 35 & $7-170$ & 40.7 & 32.2 & 33 & 14 & $14-53$ & 25.9 & 10.8 & 23.5 & 0.08 \\
\hline & $\begin{array}{c}W+M / \\
K+M\end{array}$ & 66 & $7-170$ & 33 & 26.5 & 26.5 & 30 & $9-76$ & 24.6 & 14 & 22 & 0.1 \\
\hline \multirow{3}{*}{ AST [U/] } & $W / K$ & 31 & $13-53$ & 23.4 & 8.7 & 21 & 16 & $12-53$ & 22.6 & 9.9 & 21 & 0.6 \\
\hline & $M$ & 35 & $17-132$ & 31 & 21.4 & 23 & 14 & $13-34$ & 21.4 & 5.2 & 20.5 & 0.06 \\
\hline & $\begin{array}{c}W+M / \\
K+M\end{array}$ & 66 & $13-132$ & 27.4 & 17 & 23 & 30 & $12-53$ & 22 & 7.9 & 20.5 & 0.08 \\
\hline \multirow{3}{*}{ GGT [U/l] } & $W / K$ & 31 & $9-284$ & 44.8 & 64.9 & 25 & 16 & $11-102$ & 27.8 & 23.2 & 23.5 & 0.3 \\
\hline & $M$ & 35 & | 5-846 & 89.3 & 142 & 46 & 14 & $16-34$ & 24.9 & 5.9 & 24.5 & 0.0003 \\
\hline & $\begin{array}{c}W+M / \\
K+M\end{array}$ & 66 & $9-846$ & 68.4 & 114 & 35 & 30 & $1 \mid-102$ & 26.5 & 17.2 & 24 & 0.02 \\
\hline
\end{tabular}


Table 4. Comparison of liver function parameters in patients with psoriasis with PASI $>10$ and PASI $\leq 10$

Tabela 4. Porównanie parametrów wydolności watroby między chorymi na łuszczycę z PASI > 10 i PASI $\leq 10$

\begin{tabular}{|c|c|c|c|c|c|c|c|c|c|c|c|c|}
\hline \multirow{2}{*}{$\begin{array}{l}\text { Parameter/ } \\
\text { Parametr }\end{array}$} & \multirow[t]{2}{*}{ Sex/Płeć } & \multicolumn{5}{|c|}{ PASI $>10$} & \multicolumn{5}{|c|}{$\mathrm{PASI} \leq 10$} & \multirow[t]{2}{*}{$P$} \\
\hline & & $N$ & Min.-max. & $\bar{x}$ & SD/OS & $\mathrm{Me}$ & $N$ & Min.-max. & $\bar{x}$ & SD/OS & $\mathrm{Me}$ & \\
\hline \multirow{3}{*}{$\begin{array}{l}\text { bilirubin/ } \\
\text { bilirubina } \\
{[\mathrm{mg} / \mathrm{dl}]}\end{array}$} & $W / K$ & 22 & $0.3-1.2$ & 0.6 & 0.2 & 0.6 & 9 & $0.3-0.7$ & 0.5 & 0.1 & 0.5 & 0.3 \\
\hline & M & 23 & $0.1-1.3$ & 0.6 & 0.3 & 0.6 & 12 & $0.5-6.4$ & 1.2 & 1.7 & 0.7 & 0.2 \\
\hline & $\begin{array}{c}W+M / \\
K+M\end{array}$ & 45 & $0.1-1.3$ & 0.6 & 0.3 & 0.6 & 21 & $0.3-6.4$ & 0.9 & 1.3 & 0.7 & 0.5 \\
\hline \multirow{3}{*}{$\mathrm{ALT}[\mathrm{U} / 1]$} & $W / K$ & 22 & $11-60$ & 22.3 & 10.9 & 21.5 & 9 & $7-65$ & 29.2 & 20.3 & 25 & 0.5 \\
\hline & M & 23 & $11-170$ & 38.9 & 34.7 & 27 & 12 & $7-105$ & 44.3 & 27.8 & 37.5 & 0.2 \\
\hline & $\begin{array}{c}W+M / \\
K+M\end{array}$ & 45 & $11-170$ & 30.8 & 27 & 24 & 21 & $7-105$ & 37.9 & 25.5 & 33 & 0.1 \\
\hline \multirow{3}{*}{ AST [U/] } & $\mathrm{W} / \mathrm{K}$ & 22 & $13-53$ & 23.1 & 8.5 & 21.5 & 9 & | 4-46 & 24 & 9.7 & 21 & 1 \\
\hline & M & 23 & $17-132$ & 30.5 & 24.6 & 23 & 12 & $17-66$ & 32 & 14.3 & 27.5 & 0.2 \\
\hline & $\begin{array}{c}W+M / \\
K+M\end{array}$ & 45 & $13-132$ & 26.9 & 18.7 & 22 & 21 & $14-66$ & 28.6 & 12.9 & 24 & 0.2 \\
\hline \multirow{3}{*}{ GGT [U/l] } & $W / K$ & 22 & $9-284$ & 51.9 & 75.9 & 24.5 & 9 & $10-52$ & 27.3 & 13.6 & 26 & 0.85 \\
\hline & M & 23 & 15-846 & 91.3 & 172.3 & 40 & 12 & $22-184$ & 85.6 & 54.3 & 75.5 & 0.1 \\
\hline & $\begin{array}{c}W+M / \\
K+M\end{array}$ & 45 & $9-846$ & 72 & 134.1 & 34 & 21 & $10-184$ & 60.6 & 50.7 & 41 & 0.4 \\
\hline
\end{tabular}

$N$ - number of persons, $W$ - women, $M$ - men, $\bar{x}$ - mean, SD - standard deviation, Me - median, ALT - alanine aminotransferase, AST - aspartate aminotransferase, GGT - $\gamma$-glutamyltransferase.

$N$ - liczba osób, K - kobiety, M - mężczyźni, $\bar{x}$-średnia, OS - odchylenie standardowe, Me - mediana, ALT - aminotransferaza alaninowa, AST - aminotransferaza asparaginianowa, GGT - $\gamma$-glutamylotransferaza.

Table 5. Comparison of liver function parameters in patients with psoriasis with and without metabolic syndrome

Tabela 5. Porównanie parametrów wydolności wątroby między chorymi na łuszczycę z towarzyszącym zespołem metabolicznym i bez niego

\begin{tabular}{|c|c|c|c|c|c|c|c|c|c|c|c|c|}
\hline \multirow[t]{2}{*}{$\begin{array}{l}\text { Parameter/ } \\
\text { Parametr }\end{array}$} & \multirow[t]{2}{*}{ Sex/Płeć } & \multicolumn{5}{|c|}{$\begin{array}{l}\text { Metabolic syndrome/ } \\
\text { Zespół metaboliczny }\end{array}$} & \multicolumn{5}{|c|}{$\begin{array}{l}\text { Non-metabolic syndrome/ } \\
\text { Brak zespołu metabolicznego }\end{array}$} & \multirow[t]{2}{*}{$P$} \\
\hline & & $N$ & Min.-max. & $\bar{x}$ & SD/OS & $\mathrm{Me}$ & $N$ & Min.-max. & $\bar{x}$ & SD/OS & $\mathrm{Me}$ & \\
\hline \multirow{3}{*}{$\begin{array}{l}\text { bilirubin/ } \\
\text { bilirubina } \\
{[\mathrm{mg} / \mathrm{dl}]}\end{array}$} & $\mathrm{W} / \mathrm{K}$ & 16 & $0.3-1.2$ & 0.6 & 0.2 & 0.5 & 15 & $0.3-1.2$ & 0.6 & 0.2 & 0.5 & 0.6 \\
\hline & $M$ & 9 & $0.3-0.9$ & 0.6 & 0.2 & 0.6 & 26 & $0.1-6.4$ & 0.9 & 1.2 & 0.7 & I \\
\hline & $\begin{array}{l}W+M / \\
K+M\end{array}$ & 25 & $0.3-1.2$ & 0.6 & 0.2 & 0.6 & 41 & $0.1-6.4$ & 0.8 & 0.9 & 0.6 & 0.3 \\
\hline \multirow{3}{*}{$\mathrm{ALT}[\mathrm{U} / \mathrm{l}]$} & $\mathrm{W} / \mathrm{K}$ & 16 & ||$-65$ & 28.7 & 17.5 & 25.5 & 15 & $7-34$ & 19.7 & 8.1 & 16 & 0.08 \\
\hline & $M$ & 9 & | I-86 & 47 & 24.2 & 39 & 26 & $7-170$ & 38.6 & 34.7 & 28.5 & 0.2 \\
\hline & $\begin{array}{l}W+M / \\
K+M\end{array}$ & 25 & | |-86 & 35.3 & 21.6 & 27 & 41 & $7-170$ & 31.7 & 29.3 & 25 & 0.3 \\
\hline \multirow{3}{*}{ AST [U/l] } & $\mathrm{W} / \mathrm{K}$ & 16 & $13-53$ & 25.2 & 11 & 22.5 & 15 & $14-32$ & 21.4 & 4.8 & 21 & 0.2 \\
\hline & $M$ & 9 & $18-59$ & 33.3 & 14.7 & 29 & 26 & $17-132$ & 30.2 & 23.5 & 23 & 0.5 \\
\hline & $\begin{array}{l}W+M / \\
K+M\end{array}$ & 25 & $13-59$ & 28.1 & 12.8 & 24 & 41 & $14-132$ & 27 & 19.3 & 23 & 0.4 \\
\hline \multirow{3}{*}{ GGT [U/l] } & $\mathrm{W} / \mathrm{K}$ & 16 & $9-274$ & 48 & 63.6 & 28 & 15 & $10-284$ & 41.3 & 68.3 & 24 & 0.4 \\
\hline & $M$ & 9 & $19-225$ & 68.9 & 71.3 & 28 & 26 & | 5-846 & 96.4 & 160 & 46 & 0.4 \\
\hline & $\begin{array}{l}W+M / \\
K+M\end{array}$ & 25 & $9-274$ & 55.5 & 65.8 & 28 & 41 & $10-846$ & 76.3 & 135.5 & 277 & 0.4 \\
\hline
\end{tabular}

$N$ - number of persons, $W$ - women, $M$ - men, $\bar{x}$ - mean, SD - standard deviation, Me - median, ALT - alanine aminotransferase, AST - aspartate aminotransferase, GGT - $\gamma$-glutamyltransferase.

$N$ - liczba osób, W - kobiety, M - mężczyźni, $\bar{x}$ - średnia, OS - odchylenie standardowe, Me - mediana, ALT - aminotransferaza alaninowa, AST - aminotransferaza asparaginianowa, GGT - $\gamma$-glutamylotransferaza. 
Table 6. Comparison of liver function parameters in patients with psoriasis with well-balanced diet and poorly balanced diet Tabela 6. Porównanie parametrów wydolności wątroby między chorymi na łuszczycę stosujq̨cymi dobrze i żle zbilansowanq dietę

\begin{tabular}{|c|c|c|c|c|c|c|c|c|c|c|c|c|}
\hline \multirow[t]{2}{*}{$\begin{array}{l}\text { Parameter/ } \\
\text { Parametr }\end{array}$} & \multirow[t]{2}{*}{ Sex/Płeć } & \multicolumn{5}{|c|}{$\begin{array}{c}\text { Well-balanced diet/ } \\
\text { Dobrze zbilansowana dieta }\end{array}$} & \multicolumn{5}{|c|}{$\begin{array}{l}\text { Poorly balanced diet/ } \\
\text { Źle zbilansowana dieta }\end{array}$} & \multirow[t]{2}{*}{$P$} \\
\hline & & $N$ & Min.-max. & $\bar{x}$ & SD/OS & $\mathrm{Me}$ & $N$ & Min.-max. & $\bar{x}$ & SD/OS & $\mathrm{Me}$ & \\
\hline \multirow{3}{*}{$\begin{array}{l}\text { bilirubin/ } \\
\text { bilirubina } \\
{[\mathrm{mg} / \mathrm{dl}]}\end{array}$} & $\mathrm{W} / \mathrm{K}$ & 16 & $0.3-1.2$ & 0.6 & 0.2 & 0.5 & 15 & $0.4-1.2$ & 0.6 & 0.2 & 0.5 & I \\
\hline & $M$ & 10 & $0.1-0.9$ & 0.6 & 0.2 & 0.7 & 25 & $0.1-6.4$ & 0.9 & 1.2 & 0.6 & I \\
\hline & $\begin{array}{l}W+M / \\
K+M\end{array}$ & 26 & $0.1-1.2$ & 0.6 & 0.2 & 0.6 & 40 & $0.1-6.4$ & 0.8 & I & 0.6 & 0.8 \\
\hline \multirow{3}{*}{$\mathrm{ALT}[\mathrm{U} /]$} & $\mathrm{W} / \mathrm{K}$ & 16 & $11-60$ & 26.5 & 14.7 & 24.5 & 15 & $7-65$ & 22 & 13.9 & 18 & 0.4 \\
\hline & M & 10 & $11-86$ & 37 & 22.4 & 34 & 25 & $7-170$ & 42.2 & 35.6 & 31 & 0.9 \\
\hline & $\begin{array}{l}W+M / \\
K+M\end{array}$ & 26 & $1 \mid-86$ & 30.5 & 18.4 & 26.5 & 40 & $7-170$ & 34.7 & 30.8 & 26.5 & 0.9 \\
\hline \multirow{3}{*}{ AST [U/] } & $\mathrm{W} / \mathrm{K}$ & 16 & $13-53$ & 24.6 & 9.1 & 23.5 & 15 & |4-46 & 22 & 8.2 & 19 & 0.2 \\
\hline & M & 10 & $|8-5|$ & 25.2 & 9.8 & 23.5 & 25 & $17-132$ & 33.4 & 24.4 & 23 & 0.5 \\
\hline & $\begin{array}{l}W+M / \\
K+M\end{array}$ & 26 & 13-53 & 24.8 & 9.2 & 23.5 & 40 & $14-132$ & 29.1 & 20.5 & 22.5 & I \\
\hline \multirow{3}{*}{ GGT [U/l] } & $\mathrm{W} / \mathrm{K}$ & 16 & |4-274 & 47.9 & 63 & 27 & 15 & $9-284$ & 41.5 & 68.9 & 20 & 0.2 \\
\hline & $M$ & 10 & $|5-| 4 \mid$ & 47.2 & 36.7 & 36.5 & 25 & 17-846 & 106.2 & 164.4 & 58 & 0.1 \\
\hline & $\begin{array}{l}W+M / \\
K+M\end{array}$ & 26 & |4-274 & 47.6 & 53.5 & 29 & 40 & $9-846$ & 81.9 & 139.1 & 41 & 0.4 \\
\hline
\end{tabular}

$N$ - number of persons, $W$ - women, $M$ - men, $\bar{x}$ - mean, SD - standard deviation, Me - median, ALT - alanine aminotransferase, AST - aspartate aminotransferase, GGT - $\gamma$-glutamyltransferase.

$N$ - liczba osób, W - kobiety, M - mężczyźni, $\bar{x}$-średnia, OS - odchylenie standardowe, Me - mediana, ALT - aminotransferaza alaninowa, AST - aminotransferaza asparaginianowa, GGT - $\gamma$-glutamylotransferaza.

Table 7. Comparison of liver function parameters in smoking and non-smoking patients with psoriasis

Tabela 7. Porównanie parametrów wydolności wątroby między palq̨cymi i niepalq̨cymi chorymi na łuszczycę

\begin{tabular}{|c|c|c|c|c|c|c|c|c|c|c|c|c|}
\hline \multirow{2}{*}{$\begin{array}{l}\text { Parameter/ } \\
\text { Parametr }\end{array}$} & \multirow[t]{2}{*}{ Sex/Płeć } & \multicolumn{5}{|c|}{ Smoking/Pacjenci palący } & \multicolumn{5}{|c|}{ Non-smoking/Pacjenci niepalący } & \multirow[t]{2}{*}{$P$} \\
\hline & & $N$ & Min.-max. & $\overline{\bar{x}}$ & $\mathrm{SD} / \mathrm{OS}$ & $\mathrm{Me}$ & $N$ & Min.-max. & $\overline{\bar{x}}$ & SD/OS & $\mathrm{Me}$ & \\
\hline \multirow{3}{*}{$\begin{array}{l}\text { bilirubin/ } \\
\text { bilirubina } \\
{[\mathrm{mg} / \mathrm{dl}]}\end{array}$} & $\mathrm{W} / \mathrm{K}$ & 9 & $0.3-0.7$ & 0.5 & 0.1 & 0.5 & 22 & $0.3-1.2$ & 0.6 & 0.2 & 0.5 & 0.8 \\
\hline & M & 21 & $0.1-1.3$ & 0.6 & 0.3 & 0.6 & 14 & $0.3-6.4$ & 1.1 & 1.6 & 0.7 & 0.2 \\
\hline & $\begin{array}{c}W+M / \\
K+M\end{array}$ & 30 & $0.1-1.3$ & 0.6 & 0.2 & 0.6 & 36 & $0.3-6.4$ & 0.8 & । & 0.7 & 0.6 \\
\hline \multirow{3}{*}{$\mathrm{ALT}[\mathrm{U} / \mathrm{]}$} & $\mathrm{W} / \mathrm{K}$ & 9 & $11-65$ & 24.7 & 16.6 & 22 & 22 & $7-60$ & 24.2 & 13.6 & 23 & I \\
\hline & M & 21 & $7-87$ & 37.7 & 24.3 & 31 & 14 & $12-170$ & 45.4 & 42 & 34 & 0.7 \\
\hline & $\begin{array}{c}W+M / \\
K+M\end{array}$ & 30 & $7-87$ & 33.8 & 22.8 & 25.5 & 36 & $7-170$ & 32.4 & 29.6 & 27 & 0.7 \\
\hline \multirow{3}{*}{ AST [U/] } & $\mathrm{W} / \mathrm{K}$ & 9 & $13-46$ & 23.9 & 9.3 & 22 & 22 & $14-53$ & 23.1 & 8.7 & 20.5 & 0.7 \\
\hline & $M$ & 21 & $17-59$ & 28 & 12.5 & 23 & 14 & $18-132$ & 356 & 30.4 & 23.5 & 0.4 \\
\hline & $\begin{array}{c}W+M / \\
K+M\end{array}$ & 30 & $13-59$ & 26.7 & 11.6 & 22.5 & 36 & $14-132$ & 28 & 20.6 & 23 & 0.9 \\
\hline \multirow{3}{*}{ GGT [U/l] } & $\mathrm{W} / \mathrm{K}$ & 9 & $9-284$ & 59.9 & 85.5 & 29 & 22 & $10-274$ & 38.6 & 55.6 & 24.5 & 0.3 \\
\hline & $M$ & 21 & 19-225 & 79.2 & 60.8 & 54 & 14 & $15-846$ & 104.6 & 215.9 & 43.5 & 0.3 \\
\hline & $\begin{array}{c}W+M / \\
K+M\end{array}$ & 30 & $9-284$ & 73.4 & 68.2 & 42 & 36 & 10-846 & 64.3 & 142.3 & 26.5 & 0.02 \\
\hline
\end{tabular}

$N$ - number of persons, $W$ - women, $M$ - men, $\bar{x}$ - mean, SD - standard deviation, Me - median, ALT - alanine aminotransferase, AST - aspartate aminotransferase, GGT - $\gamma$-glutamyltransferase.

$N$ - liczba osób, W - kobiety, M - mężczyźni, $\bar{x}$ - średnia, OS - odchylenie standardowe, Me - mediana, ALT - aminotransferaza alaninowa, AST - aminotransferaza asparaginianowa, GGT - $\gamma$-glutamylotransferaza. 
Table 8. Comparison of liver function parameters in patients with psoriasis with positive and negative family history Tabela 8. Porównanie parametrów wydolności wątroby między chorymi na łuszczycę z dodatnim i ujemnym wywiadem rodzinnym

\begin{tabular}{|c|c|c|c|c|c|c|c|c|c|c|c|c|}
\hline \multirow[t]{2}{*}{$\begin{array}{l}\text { Parameter/ } \\
\text { Parametr }\end{array}$} & \multirow[t]{2}{*}{ Sex/Płeć } & \multicolumn{5}{|c|}{$\begin{array}{l}\text { Positive family history/ } \\
\text { Dodatni wywiad rodzinny }\end{array}$} & \multicolumn{5}{|c|}{$\begin{array}{l}\text { Negative family history/ } \\
\text { Ujemny wywiad rodzinny }\end{array}$} & \multirow[t]{2}{*}{$P$} \\
\hline & & $N$ & Min.-max. & $\bar{x}$ & SD/OS & $\mathrm{Me}$ & $N$ & Min.-max. & $\bar{x}$ & SD/OS & $\mathrm{Me}$ & \\
\hline \multirow{3}{*}{$\begin{array}{l}\text { bilirubin/ } \\
\text { bilirubina } \\
\text { [mg/dl] }\end{array}$} & $\mathrm{W} / \mathrm{K}$ & 17 & $0.3-1.2$ & 0.6 & 0.2 & 0.5 & 14 & $0.34-1.2$ & 0.6 & 0.3 & 0.5 & 0.8 \\
\hline & $M$ & 19 & $0.1-1.3$ & 0.7 & 0.3 & 0.7 & 16 & $0.4-6.4$ & 1 & 1.5 & 0.6 & 0.9 \\
\hline & $\begin{array}{c}W+M / \\
K+M\end{array}$ & 36 & $0.1-1.3$ & 0.6 & 0.3 & 0.6 & 30 & $0.34-6.4$ & 0.8 & 1.1 & 0.6 & 1 \\
\hline \multirow{3}{*}{$\mathrm{ALT}[\mathrm{U} / \mathrm{I}]$} & $\mathrm{W} / \mathrm{K}$ & 17 & $11-65$ & 27 & 14.6 & 25 & 14 & $7-60$ & 21.1 & 13.7 & 16.5 & 0.1 \\
\hline & M & 19 & $12-87$ & 40.1 & 24 & 37 & 16 & $7-170$ & 41.6 & 40.7 & 32 & 0.6 \\
\hline & $\begin{array}{c}W+M / \\
K+M\end{array}$ & 36 & $1 \mid-87$ & 33.9 & 20.9 & 27 & 30 & $7-170$ & 32 & 32.4 & 24 & 0.2 \\
\hline \multirow{3}{*}{ AST [U/I] } & $W / K$ & 17 & $13-53$ & 25.6 & 9.9 & 24 & 14 & $14-32$ & 20.6 & 6.1 & 18 & 0.08 \\
\hline & M & 19 & $18-59$ & 29.1 & 12.6 & 23 & 16 & $17-132$ & 33.4 & 28.9 & 24.5 & 0.8 \\
\hline & $\begin{array}{c}W+M / \\
K+M\end{array}$ & 36 & $13-59$ & 27.4 & 11.4 & 23 & 30 & $14-132$ & 27.4 & 22.2 & 21 & 0.2 \\
\hline \multirow{3}{*}{ GGT [U/] } & $\mathrm{W} / \mathrm{K}$ & 17 & $10-284$ & 61.4 & 83.4 & 29 & 14 & 9-81 & 24.6 & 18.7 & 19 & 0.03 \\
\hline & $M$ & 19 & I5-225 & 65.1 & 55.2 & 46 & 16 & $21-846$ & 118.1 & 201 & 49.5 & 0.7 \\
\hline & $\begin{array}{l}W+M / \\
K+M\end{array}$ & 36 & 10-284 & 63.3 & 69 & 41 & 30 & $9-846$ & 74.5 & 152.7 & 26.5 & 0.25 \\
\hline
\end{tabular}

$N$ - number of persons, $\mathrm{W}$ - women, $M$ - men, $\bar{x}$ - mean, SD - standard deviation, Me - median, ALT - alanine aminotransferase, AST - aspartate aminotransferase, GGT - $\gamma$-glutamyltransferase.

$N$ - liczba osób, W - kobiety, M - mężczyźni, $\bar{x}$ - średnia, OS - odchylenie standardowe, Me - mediana, ALT - aminotransferaza alaninowa, AST - aminotransferaza asparaginianowa, GGT - $\gamma$-glutamylotransferaza.

notransferase - AST and bilirubin) do not differ significantly between healthy individuals and patients with psoriasis (Table 3), persons following a balanced and non-balanced diet (Table 6), with a different severity of psoriasis (Table 4), smokers and non-smokers (Table 7), or with positive and negative family history (Table 8).

There were no differences in the values of laboratory tests in patients with severe or moderate psoriasis (PASI > 10) compared to patients with mild form of the disease (PASI $\leq 10)$ (Table 4).

It was shown that the persons who applied systemic treatment in the past (methotrexate, cyclosporin A, retinoids and PUVA therapy) presented a significantly lower concentration of bilirubin as compared to patients who did not receive any systemic treatment ( $p=0.04$; Table 9). Treatment applied in the past had no impact on the other liver parameters (ALT, AST, GGT).

There was a negative correlation between bilirubin level and the age of patients $(p=0.02)$ and the bilirubin and C-reactive protein (CRP) concentration $(p=0.03)$. Activity of ALT correlated positively with abdominal circumference $(p=0.01)$, uric acid $(p=0.004)$ and BMI $(p=0.001)$. Activity of AST correlated positively with abdominal circumference $(p=$ $0.001)$, uric acid concentration $(p=0.03)$ and BMI $(p$ $=0.001)$. Additionally, the increase in concentration między osobami zdrowymi a chorymi na łuszczycę (tab. 3), osobami stosującymi dietę zbilansowaną i niezbilansowaną (tab. 6), o różnym nasileniu łuszczycy (tab. 4), palącymi i niepalącymi (tab. 7) i osobami z dodatnim i ujemnym wywiadem rodzinnym (tab. 8).

Nie stwierdzono także różnic pod względem wyników badań laboratoryjnych między pacjentami z ciężką i umiarkowaną postacią łuszczycy (PASI $>10$ ) a pacjentami z łuszczycą o łagodnym nasileniu $(\mathrm{PASI} \leq 10)($ tab. 4).

Wykazano, że u osób, które były wcześniej leczone ogólnie (metotreksatem, cyklosporyną A, retinoidami oraz PUVA) stężenie bilirubiny jest istotnie mniejsze niż u chorych nieleczonych wcześniej ogólnie $(p=0,04 ;$ tab. 9). Uprzednie leczenie nie miało wpływu na inne wskaźniki wydolności wątroby (ALT, AST, GGT).

Stwierdzono ujemną korelację między stężeniem bilirubiny a wiekiem pacjentów $(p=0,02)$ i między stężeniem bilirubiny a CRP $(p=0,03)$. Dodatnią korelację zaobserwowano między aktywnością ALT a obwodem brzucha $(p=0,01)$, stężeniem kwasu moczowego $(p=0,004)$ i BMI $(p=0,001)$. Podobną dodatnią zależność wykazano między aktywnością AST a obwodem brzucha ( $p=0001)$, stężeniem kwasu moczowego $(p=0,03)$ i BMI $(p=0,001)$. Dodatkowo stwierdzono, że wzrost aktywności ALT jest proporcjonalny do wzrostu stężenia cholesterolu $(p=0,01)$, 
Table 9. Comparison of liver function parameters in patients with psoriasis treated with oral medications in the past and not treated with oral medications in the past

Tabela 9. Porównanie parametrów wydolności wątroby między chorymi na łuszczycę leczonymi i nieleczonymi w przeszłości lekami doustnymi

\begin{tabular}{|c|c|c|c|c|c|c|c|c|c|c|c|c|}
\hline \multirow[t]{2}{*}{$\begin{array}{l}\text { Parameter/ } \\
\text { Parametr }\end{array}$} & \multirow[t]{2}{*}{ Sex/Płeć } & \multicolumn{5}{|c|}{$\begin{array}{l}\text { Oral treatment in the past/ } \\
\text { Pacjenci leczeni lekami doustnymi } \\
\text { w przeszłości }\end{array}$} & \multicolumn{5}{|c|}{$\begin{array}{l}\text { No oral treatment in the past/ } \\
\text { Pacjenci nieleczeni lekami doustnymi } \\
\text { w przeszłości }\end{array}$} & \multirow[t]{2}{*}{$P$} \\
\hline & & $N$ & Min.-max. & $\bar{x}$ & SD/OS & $\mathrm{Me}$ & $N$ & Min.-max. & $\bar{x}$ & SD/OS & $\mathrm{Me}$ & \\
\hline \multirow{3}{*}{$\begin{array}{l}\text { bilirubin/ } \\
\text { bilirubina } \\
{[\mathrm{mg} / \mathrm{dl}]}\end{array}$} & $W / K$ & 4 & $0.3-0.7$ & 0.5 & 0.2 & 0.5 & 27 & $0.34-1.2$ & 0.6 & 0.3 & 0.3 & 0.6 \\
\hline & $M$ & 8 & $0.1-0.9$ & 0.5 & 0.3 & 0.4 & 27 & $0.1-6.4$ & 0.9 & 1.1 & 0.7 & 0.06 \\
\hline & $\begin{array}{l}W+M / \\
K+M\end{array}$ & 12 & $0.1-0.9$ & 0.5 & 0.2 & 0.5 & 30 & $0.34-6.4$ & 0.8 & 1.1 & 0.6 & 0.04 \\
\hline \multirow{3}{*}{$\mathrm{ALT}[\mathrm{U} / 1]$} & $\mathrm{W} / \mathrm{K}$ & 4 & $16-65$ & 33 & 22.1 & 25.5 & 27 & $7-60$ & 23 & 13.7 & 12.9 & 0.3 \\
\hline & $M$ & 8 & $18-46$ & 32.9 & 9 & 34.5 & 27 & $7-170$ & 43.1 & 36.2 & 33 & 0.8 \\
\hline & $\begin{array}{l}W+M / \\
K+M\end{array}$ & 12 & $16-65$ & 32.9 & 13.6 & 30.5 & 30 & $7-170$ & 32 & 32.4 & 24 & 0.2 \\
\hline \multirow{3}{*}{ AST [U/] } & $\mathrm{W} / \mathrm{K}$ & 4 & $21-46$ & 28 & 12.1 & 22.5 & 27 & $13-53$ & 22.7 & 6.1 & 8.1 & 0.3 \\
\hline & $M$ & 8 & $18-32$ & 24 & 5.2 & 22 & 27 & $17-132$ & 33.1 & 23.9 & 24 & 0.6 \\
\hline & $\begin{array}{l}W+M / \\
K+M\end{array}$ & 12 & | 8-46 & 25.3 & 7.8 & 22 & 30 & $14-132$ & 27.4 & 22.2 & 21 & 0.7 \\
\hline \multirow{3}{*}{ GGT [U/l] } & $\mathrm{W} / \mathrm{K}$ & 4 & 24-284 & 95.5 & 126 & 37 & 27 & $9-274$ & 37.3 & 18.7 & 50.7 & 0.1 \\
\hline & $M$ & 8 & $21-100$ & 52.3 & 26.9 & 44 & 27 & I5-846 & 100.3 & 160.1 & 46 & 0.8 \\
\hline & $\begin{array}{c}W+M / \\
K+M\end{array}$ & 12 & $21-284$ & 66.7 & 72.4 & 43.5 & 30 & $9-846$ & 74.5 & 152.7 & 26.5 & 0.2 \\
\hline
\end{tabular}

$N$ - number of persons, $W$ - women, $M$ - men, $\bar{x}$ - mean, SD - standard deviation, Me - median, ALT - alanine aminotransferase, AST - aspartate aminotransferase, GGT - $\gamma$-glutamyltransferase.

$N$ - liczba osób, W - kobiety, M - mężczyźni, $\bar{x}$ - średnia, OS - odchylenie standardowe, Me - mediana, ALT - aminotransferaza alaninowa, AST - aminotransferaza asparaginianowa, GGT - $\gamma$-glutamylotransferaza.

Table 10. Positive correlations

Tabela 10. Dodatnie korelacje

\begin{tabular}{lc} 
Correlations/Korelacje & $P$ \\
bilirubin vs. age/bilirubina vs wiek & 0.02 \\
\hline bilirubin vs. CRP/bilirubina vs CRP & 0.03 \\
\hline ALT vs. waist circumference/ALT vs obwód pasa & 0.001 \\
\hline ALT vs. uric acid/ALT vs kwas moczowy & 0.004 \\
\hline ALT vs. cholesterol/ALT vs cholesterol & 0.01 \\
\hline ALT vs. LDL & 0.002 \\
\hline ALT vs. apoB & 0.03 \\
\hline ALT vs. BMI & 0.001 \\
\hline AST vs. waist circumference/AST vs obwód pasa & 0.01 \\
\hline AST vs. uric acid/AST vs kwas moczowy & 0.03 \\
\hline AST vs. BMI & 0.001 \\
\hline GGT vs. uric acid/GGT vs kwas moczowy & 0.008 \\
\hline GGT vs. cholesterol & 0.04 \\
\hline GGT vs. TG & 0.04 \\
\hline GGT vs. apoB & 0.03 \\
\hline CRP - C-reactive protein, ALT - alanine aminotransferase, AST - aspartate aminotransferase, GGT - $\gamma$-glutamyl- \\
transferase, LDL - low density lipoprotein, apoB - apolipoprotein B, BMI - body mass index, TG - triglycerides. \\
CRP - biatko C-reaktywne, ALT - aminotransferaza alaninowa, AST - aminotransferaza asparaginianowa, \\
GGT - $\gamma$-glutamylotransferaza, LDL - lipoproteina o matej gęstości, apoB - apolipoproteina B, BMI - wskaźnik \\
masy ciata, TG - trójglicerydy. &
\end{tabular}


of ALT activity was proportional to the increase in concentration of cholesterol $(p=0.01)$, apolipoprotein $\mathrm{B}(\mathrm{apoB})(p=0.03)$ and apoB/apoA1 ratio $(p=$ $0.03)$. The GGT activity correlated positively with the concentration of uric acid $(p=0.008)$, cholesterol $(p=$ $0.04)$, triglycerides (TG) $(p=0.04)$, apoB $(p=0.03)$ and apoB/apoA1 $(p=0.002)$ (Table 10).

\section{DISCUSSION}

Non-alcoholic fatty liver disease accounts for $90 \%$ cases of elevated liver enzymes with no underlying cause of the disease [4]. Insulin resistance, oxidative stress and chronic inflammation contribute to initiation and progress of pathological changes in NAFLD. Obesity and diabetes type 2 are risk factors predisposing to occurrence of the disease [2]. Since NAFLD was considered as a hepatic manifestation of the metabolic syndrome, a higher frequency of cardiovascular diseases in these patients has been observed [5].

Aspartate aminotransferase is a transaminase catalyzing the reaction of transfer of the amine group from L-asparagine to 2-oxoglutarate as a result of which an oxaloacetate and L-glutamine form. Aspartate aminotransferase is present in the cytoplasm and mitochondria of hepatocytes and skeletal and cardiac muscles cells.

Alanine aminotransferase is an enzyme catalyzing the reaction of transfer of the amine group from L-alanine to 2-oxoglutarate as a result of which L-glutamine and pyruvate are synthesized. Alanine aminotransferase present in the serum derives mainly from the cytoplasm of hepatocytes and is a more specific marker for the liver than AST.

In the conducted trial, ALT and AST activity was similar in the group of patients with psoriasis and healthy individuals. Van der Voort et al. [6], likewise, did not observe any increased activity of AST and ALT in patients with psoriasis as compared to healthy subjects. Narayanasamy et al. [7], on the other hand, concluded that patients with psoriasis with NAFLD had higher AST and ALT activity, as well as a larger abdominal circumference and higher TG concentrations as compared to patients with psoriasis not suffering from NAFLD. The authors also found that more severe forms of psoriasis and hyperglycemia occurred in NAFLD patients. Moreover, the patients participating in the trial were suffering from psoriasis for a significantly longer period of time. Our results are different since we did not observe any relation between ALT and AST activity and severity of psoriasis or its duration.

Based on the trial it may be concluded that the aminotransferases concentration does not depend on the psoriasis process itself. Aspartate aminotrans- apolipoproteiny B (apoB) $(p=0,03)$ oraz apoB/apoA1 $(p=0,03)$. Aktywność GGT wykazała dodatnią korelację ze stężeniem kwasu moczowego $(p=0,008)$, cholesterolu $(p=0,04)$, trójglicerydów (TG) $(p=0,04)$, apoB $(p=0,03)$ i apoB/apoA1 $(p=0,002)($ tab. 10).

\section{OMÓWIENIE}

Niealkoholowa stłuszczeniowa choroba wątroby odpowiada za 90\% przypadków podwyższonej aktywności enzymów wątrobowych przy braku pierwotnej przyczyny schorzenia [4]. Do powstawania i progresji zmian patologicznych w przebiegu NAFLD przyczyniają się takie zaburzenia, jak insulinooporność, stres oksydacyjny i przewlekły stan zapalny. Czynnikami ryzyka sprzyjającymi rozwojowi choroby są otyłość oraz cukrzyca typu 2 [2]. Ponieważ NAFLD uznano za wątrobową manifestację zespołu metabolicznego, u pacjentów obserwowano zwiększoną częstość występowania chorób układu krążenia [5].

Aminotransferaza asparaginianowa jest transaminazą, która katalizuje reakcje przeniesienia grupy aminowej z L-asparaginy do 2-oksoglutaranu, wskutek której powstaje oksalooctan i L-glutamina. Aminotransferaza asparaginianowa znajduje się w cytoplazmie i mitochondriach hepatocytów oraz komórkach mięśni szkieletowych i serca.

Aminotransferaza alaninowa jest enzymem, który katalizuje reakcję przeniesienia grupy aminowej z L-alaniny do 2-oksoglutaranu, wskutek której dochodzi do syntezy L-glutaminy i pirogronianu. Aminotransferaza alaninowa w surowicy pochodzi głównie z cytoplazmy hepatocytów i jest bardziej swoistym markerem wydolności wątroby niż AST.

W przeprowadzonym badaniu aktywności ALT i AST były zbliżone $\mathrm{u}$ chorych na łuszczycę oraz u zdrowych pacjentów. Van der Voort i wsp. [6] również nie wykazali podwyższonej aktywności AST i ALT u pacjentów $\mathrm{z}$ łuszczycą $\mathrm{w}$ porównaniu ze zdrowymi uczestnikami badania. Z kolei w pracy Narayanasamy i wsp. [7] stwierdzono, że u pacjentów z łuszczycą i NAFLD występuje podwyższona aktywność AST i ALT, a także większy obwód brzucha i większe stężenie TG niż u pacjentów, u których nie rozpoznano NAFLD. Autorzy wykazali większe nasilenie łuszczycy oraz hiperglikemię u pacjentów z NAFLD. Ponadto osoby uczestniczące $\mathrm{w}$ badaniu chorowały na łuszczycę przez znamiennie dłuższy czas. Uzyskane wyniki są odmienne, ponieważ nie zaobserwowano żadnej zależności między aktywnością ALT i AST a nasileniem czy czasem trwania łuszczycy.

Na podstawie badania można wysunąć wniosek, że aktywność aminotransferaz nie ma związku z procesem łuszczycowym. Aktywność AST i ALT u pacjentów z łuszczycą wykazywała jednak dodatnią korelację z obwodem brzucha, BMI i stężeniem 
ferase and ALT activity in patients with psoriasis, however, correlated positively with abdominal circumference, BMI and uric acid concentration. Moreover, ALT activity was proportional to the total cholesterol concentration and apoB/apoA1 ratio. Considering the positive correlation of these parameters with obesity, abdominal obesity and dyslipidemia, i.e. factors contributing to NAFLD development, it may be assumed that an increase in AST and ALT activity results from the liver disease with the underlying dyslipidemia and obesity.

$\gamma$-Glutamyltransferase is a cell membrane-bound glycoprotein enzyme involved in transfer of $\gamma$-glutamyl residues. It occurs in all cells except for erythrocytes. The enzyme activity is high, particularly in tissues that have absorptive and excretory functions such as the kidneys, biliary ducts, intestines, and epididymis. The organ that is almost exclusively responsible for the enzyme serum concentration is the liver.

Increased GGT activity may be observed in the course of NAFLD, and along with the hepatic steatosis progress GGT activity increases [8].

In our trial patients with psoriasis had higher GGT activity than the control group individuals, but a strong statistical difference was observed only in men. It is difficult to explain why the difference concerns only mans because the factors which can affect the activity of GGT such as alcohol consumption, age, and BMI were comparable in men and women. It is known that activity of GGT depends on menopause in women [9]. Furthermore, testosterone, human sex hormone-binding globulin and dehydroepiandrosterone are inversely associated with the change in GGT [10]. Pei et al. [11] found that GGT is the most suitable parameter among liver function tests for the prediction of metabolic syndrome but only in men. Additionally, in women GGT activity was significantly higher in those with positive family history. Our trial shows that GGT is elevated in patients with psoriasis regardless of other factors, which means that it is related to the skin disease itself. Moreover, it is possible that there exists a genetic relationship between psoriasis and an increased GGT activity since it is higher in patients with positive family history. As shown by the only study available in the literature on markers of liver function in patients with psoriasis as compared to patients treated for contact dermatitis or atopic dermatitis, hepatic parameters were significantly increased in patients with psoriasis, and it was actually GGT activity which was identified in the highest percentage of patients [12].

Furthermore, GGT increases in patients suffering from a liver disease due to a relation with dyslipidemia. In our trial it was proved that GGT activity kwasu moczowego. Ponadto aktywność ALT była proporcjonalna do stężenia cholesterolu całkowitego i stosunku apoB/apoA1. Ze względu na dodatnią zależność między aktywnością tych wskaźników a otyłością, otyłością brzuszną i dyslipidemią, czyli czynnikami sprzyjającymi rozwojowi NAFLD, można założyć, że wzrost aktywności AST i ALT jest pochodną schorzenia wątroby związanego z dyslipidemią i otyłością.

$\gamma$-Glutamylotransferaza wiąże się z błonami komórkowymi enzymu glikoproteinowego, który uczestniczy w przenoszeniu reszt $\gamma$-glutamylowych. Występuje we wszystkich komórkach poza erytrocytami. Enzym odznacza się wysoką aktywnością, zwłaszcza w tkankach, które pełnią funkcje związane z wchłanianiem i wydalaniem, takich jak nerki, przewody żółciowe, jelita i najądrza. Narządem niemal całkowicie odpowiedzialnym za aktywność enzymu w surowicy jest wątroba.

Podwyższoną aktywność GGT obserwuje się w przebiegu NAFLD i wzrasta ona wraz z progresją stłuszczenia wątroby [8].

W naszym badaniu aktywność GGT u chorych na cukrzycę była wyższa niż w grupie kontrolnej, jednak statystycznie znamienną różnicę odnotowano wyłącznie u płci męskiej. Trudno jednoznacznie stwierdzić, dlaczego różnica ta występuje tylko u mężczyzn, ponieważ czynniki o potencjalnym wpływie na aktywność GGT, takie jak spożycie alkoholu, wiek, BMI, były zbliżone u kobiet i mężczyzn. Potwierdzono, że aktywność GGT u kobiet ma związek z menopauzą [9]. Z kolei testosteron, ludzkie białko wiążące hormony płciowe oraz dehydroepiandrosteron wykazują odwrotną zależność ze zmianami aktywności GGT [10]. Pei i wsp. [11] zaobserwowali, że spośród prób wątrobowych GGT jest najbardziej przydatnym wskaźnikiem predykcyjnym zespołu metabolicznego, ale wyłącznie u mężczyzn. Ponadto u kobiet aktywność GGT była znamiennie wyższa w przypadku dodatniego wywiadu rodzinnego. Badanie wykazało podwyższone stężenie GGT u chorych na łuszczycę niezależnie od obecności innych czynników, co wskazywałoby na związek z chorobą. Nie można również wykluczyć zależności genetycznej między łuszczycą a zwiększoną aktywnością GGT, ponieważ występuje ona u chorych $\mathrm{z}$ dodatnim wywiadem rodzinnym. W jedynym dostępnym w literaturze badaniu analizującym markery wydolności wątroby u pacjentów z łuszczycą w porównaniu z pacjentami leczonymi z powodu kontaktowego lub atopowego zapalenia skóry wskaźniki wątrobowe były znamiennie podwyższone u pacjentów z łuszczycą, a podwyższoną aktywność GGT stwierdzono u najwyższego odsetka pacjentów [12].

Wzrost aktywności GGT obserwuje się również $\mathrm{u}$ pacjentów z chorobą wątroby związaną z dyslipidemią. Nasze badanie wykazało, że aktywność GGT 
correlated positively with the total cholesterol level and apoB, but not with obesity. It may be assumed that increased GGT interacts with lipoproteins containing apoB (atherogenic fractions).

It is known that GGT has a direct impact on formation of atherosclerotic plaque at the cellular and molecular level. The GGT activity in the atherosclerotic plaque correlates with the activity of GGT in serum and the histopathological index of atherosclerotic plaque destabilization. It must be emphasized that GGT in the serum, apart from albumins, also binds to low density lipoprotein (LDL) and probably owing to this binding GGT is transported to atherosclerotic plaque [13]. Emdin et al. concluded that increased GGT activity correlates positively with concentration related to lipoproteins [14].

Bilirubin is a product of heme catabolism and is transported to the liver by albumins, where it is metabolized and excreted with the bile.

In the conducted trial the patients with psoriasis had a bilirubin concentration similar to healthy individuals, whereas, which is interesting, patients that had been treated with systemic antipsoriatic drugs in the past had a lower bilirubin concentration as compared to patients receiving only topical and/or UVB $311 \mathrm{~nm}$ therapy. The bilirubin concentration correlated negatively with the CRP level and age of patients. In two other trials it was observed that bilirubin concentration was lower in patients with psoriasis than in healthy individuals. In one of the trials, similarly to our study, bilirubin concentration correlated negatively with CRP concentration [15] and in the other trial with carotid intima media thickness (CIMT) [16].

Bilirubin is an antioxidative factor, and persons with a lower bilirubin concentration have a lower total antioxidant capacity (TAC) and thus a lower anti-inflammatory potential. A negative correlation between high-sensitivity CRP (hsCRP) and bilirubin concentrations was revealed [17]. Due to the antioxidative influence of bilirubin it is an acknowledged factor acting against atherosclerotic diseases [18, 19].

Interestingly, hyperbilirubinemia caused by a liver disease does not protect against cardiovascular diseases [20].

A meta-analysis published in 2016 found a negative relation between bilirubin concentration and occurrence of diabetes type 2 . There was also a relationship between occurrence of the metabolic syndrome and a lower concentration of bilirubin [21]. Similar observations were made in obese persons in whom bilirubin concentration was lower than in the group of individuals with normal BMI [22]. Wagner et al. [23] observed a beneficial influence of bilirubin on lipid concentrations in the blood. A negative correlation was observed between bilirubin level and LDL dodatnio koreluje ze stężeniem cholesterolu całkowitego i apoB. Nie stwierdzono korelacji z otyłością. Można założyć, że istnieje zależność między podwyższoną aktywnością GGT a lipoproteinami zawierającymi apoB (frakcjami aterogennymi).

Wiadomo, że GGT bezpośrednio wpływa na powstawanie blaszki miażdżycowej na poziomie zarówno komórkowym, jak i molekularnym. Aktywność GGT w blaszce miażdżycowej wykazuje zależność z aktywnością GGT w surowicy oraz wskaźnikiem histopatologicznym destabilizacji blaszki miażdżycowej. Należy zaznaczyć, że poza albuminami również GGT w surowicy wiąże się z lipoproteinami o małej gęstości (low density lipoprotein - LDL). Prawdopodobnie wskutek tego wiązania następuje przeniesienie GGT do blaszki miażdżycowej [13]. Emdin i wsp. stwierdzili, że podwyższona aktywność GGT wykazuje dodatnią korelację ze stężeniem związanym z lipoproteinami [14].

Bilirubina jest produktem katabolizmu hemu przenoszonym przez albuminy do wątroby, gdzie jest metabolizowana i wydalana wraz z żółcią.

W naszym badaniu stężenie bilirubiny u pacjentów z łuszczycą i zdrowych osób było zbliżone. Co ciekawe, u pacjentów leczonych w przeszłości systemowymi lekami przeciwłuszczycowymi stężenie bilirubiny było mniejsze niż u chorych leczonych wyłącznie miejscowo i/lub UVB 311. Stężenie bilirubiny ujemnie korelowało z poziomem CRP i wiekiem pacjentów. W pozostałych dwóch badaniach autorzy wykazali, że stężenie bilirubiny jest mniejsze u pacjentów z łuszczycą niż u zdrowych uczestników. W jednym z badań, podobnie jak w naszym, stwierdzono ujemną korelację między stężeniem bilirubiny a CRP [15], a w drugim ujemną korelację z grubością błony wewnętrznej i środkowej ścian tętnic szyjnych (carotid intima media thickness - CIMT) [16].

Bilirubina jest czynnikiem o działaniu przeciwutleniającym, a u osób z niższym jej stężeniem występuje niższa całkowita zdolność przeciwutleniająca (total antioxidant capacity - TAC), a także mniejszy potencjał przeciwzapalny. Odnotowano również ujemną zależność między stężeniem CRP o wysokiej czułości (hsCRP) a stężeniem bilirubiny [17]. Ze względu na właściwości przeciwutleniające bilirubina jest uznanym czynnikiem działającym przeciwko chorobom miażdżycowym [18, 19].

Warto jednak przy tym dodać, że hiperbilirubinemia wywołana schorzeniem wątroby nie chroni przed chorobami układu krążenia [20].

W opublikowanej w 2016 r. metaanalizie opisano ujemną zależność między stężeniem bilirubiny a wystąpieniem cukrzycy typu 2. Odnotowano również związek między wystąpieniem zespołu metabolicznego a niższym stężeniem bilirubiny [21]. Podobnych obserwacji dokonano u osób otyłych, u których stężenie bilirubiny było niższe niż u osób z prawi- 
and a positive one between bilirubin level and high density lipoprotein (HDL). High-density lipoprotein is also a bilirubin binding molecule.

In our trial no correlation was observed between bilirubin concentration and concentration of selected lipids. However, it may be due to the fact that the sample group comprised patients with psoriasis predisposed to dyslipidemia.

Limitations of the study were the small number of participants and lack of examination of other hepatic function parameters such as albumins and international normalized ratio.

\section{CONCLUSIONS}

Psoriasis is accompanied by abnormalities in activity and concentration of some liver function markers. It mainly predisposes to increased GGT activity. In patients with psoriasis increased ALT and AST parameters probably result from liver diseases since they accompany dyslipidemia and obesity. Bilirubin level correlates adversely with aggravation of inflammation in patients with psoriasis. The analyzed factors are independent of the degree of psoriasis severity, presence of metabolic syndrome or dietary habits.

On one hand the profile of parameters of liver function in psoriasis is associated with NAFLD and on the other hand it contributes to the development of atherosclerosis.

\section{ACKNOWLEDGMENTS}

The study was funded by the Medical University of Lodz, project no. 502-03/5-064-01/502-54-171.

\section{CONFLICT OF INTEREST}

The authors declare no conflict of interest. dłowym BMI [22]. Wagner i wsp. [23] potwierdzili korzystny wpływ bilirubiny na stężenie lipidów we krwi. Wykazano ujemną korelację między stężeniem bilirubiny a LDL oraz dodatnią zależność między stężeniem bilirubiny a lipoproteinami o dużej gęstości (high density lipoprotein - HDL). HDL jest również cząsteczką wiążącą bilirubinę.

W naszym badaniu nie stwierdzono związku między stężeniem bilirubiny a niektórych lipidów. Może to jednak wynikać z faktu, że grupa badana obejmowała pacjentów z łuszczycą i skłonnością do dyslipidemii.

Ograniczeniem badania była niewielka liczba uczestników oraz brak analizy innych wskaźników wydolności wątroby, takich jak stężenie albumin i wskaźnik INR.

\section{WNIOSKI}

Łuszczycy towarzyszą zaburzenia stężenia i aktywności niektórych markerów wydolności wątroby. Choroba ta predysponuje głównie do zwiększonej aktywności GGT. U pacjentów z łuszczycą podwyższone wskaźniki ALT i AST są prawdopodobnie pochodną schorzeń wątroby, ponieważ towarzyszą dyslipidemii i otyłości. U chorych na łuszczycę stwierdza się ujemną korelację między stężeniem bilirubiny a nasileniem stanu zapalnego. Analizowane czynniki są niezależne od stopnia ciężkości łuszczycy, obecności zespołu metabolicznego oraz nawyków żywieniowych.

Z jednej strony profil wskaźników wydolności wątroby w łuszczycy jest związany z NAFLD, z drugiej natomiast przyczynia się do rozwoju miażdżycy.

\section{PODZIĘKOWANIA}

Badanie zostało sfinansowane przez Uniwersytet Medyczny w Łodzi w ramach projektu nr 502-03/ 5-064-01/502-54-171.

\section{KONFLIKT INTERESÓW}

Autorzy deklarują brak konfliktu interesów.

\section{References \\ Piśmiennictwo}

1. Boehncke W.H., Schon M.P.: Psoriaris. Lancet 2015, 386, 983-994.

2. Neuschwander-Tetri B.A.: Non-alcoholic fatty liver disease. BMC Medicine 2017, 15, 45

3. Mantovani A., Gisondi P., Lonardo A., Targher G.: Relationship between non-alcoholic fatty liver disease and psoriasis: a novel hepato-dermal axis? Int J Mol Sci 2016, 17, 217.

4. Angulo P.: Nonalcoholic fatty liver disease. N Eng J Med 2002, 346, 1221-1231.

5. Lee Y.J., Shim J.Y., Moon B.S., Shin Y.H., Jung D.H., Lee J.H., et al.: The relationship between arterial stiffness and nonalcoholic fatty liver disease. Dig Dis Sci 2012, 57, 196-203.

6. Van der Voort E.A.M., Koehler E.M., Nijsten T., Stricker B.H., Hofman A., Janssen H.L., et al.: Increased prevalence of advanced liver fibrosis in patients with psoriasis: a cross-sectional analysis from the Rotterdam Study. Acta Derm Venereol 2016, 96, 213-217. 
7. Narayanasamy K., Sanmarkan A.D., Rajendran K., Annasamy C., Ramalingam S.: Relationship between psoriasis and non-alcoholic fatty liver disease. Gastroenterology Rev 2016, 11, 263-269.

8. Kasapoglu B., Turkay C., Yalcin K.S., Carlioglu A., Koktener A.: Role of gamma-glutamyl transferase levels in prediction of high cardiovascular risk among patients with non-alcoholic fatty liver disease. Indian J Med Res 2016, 143, 30-36.

9. Nilsen O., Forde O.H., Brenn T.: The Troms Study: distribution and population determinants of gamma-glutamyltransferase. Am J Epidemiol 1990, 132, 318-326.

10. Haring R., Baumeister S.E., Volzke H., Dorr M., Kocher T., Nauck M., et al.: Prospective inverse associations of sex hormone concentrations in men with biomarkers of inflammation and oxidative stress. J Androl 2012, 33, 944-650.

11. Pei D., Hsia T.L., Chao T.T., Lin J.D., Hsu C.H., Wu C.Z., et al.: Gamma-glutamyl transpeptidase in men and alanine aminotransferase in women are the most suitable parameters among liver function tests for the prediction of metabolic syndrome in nonviral hepatitis and nonfatty liver in the elderly. Saudi J Gastroenterol 2015, 21, 158-164.

12. Finet A., Viguier M., Chazouilleres O., Amatore F., Paul C., Richard M.A., et al.: Liver test abnormalities in patients admitted for severe psoriasis: prevalence and associated risk factors. J Eur Acad Dermatol Venereol 2016, 30, 1742-1748.

13. Ndrepepa G., Kastrati A.: Gamma-glutamyltransferase and cardiovascular disease. Ann Trans Med 2016, 4, 481.

14. Emdin M., Passino C., Pompella A., Paolicchi A.: Gamma-glutamyltransferase in patients with coronary atherosclerosis. Atherosclerosis 2006, 27, 2145-2146.

15. Zhou Z.X., Chen J.K., Hong Y.Y., Zhou R., Zhou D.M., Sun L.Y., et al.: Relationship between the serum total bilirubin and inflammation in patients with psoriasis vulgaris. J Clin Lab Anal 2016, 30, 768-775.

16. Balta S., Balta I., Mikhailidis D.P., Ozturk C., Demirkol S., Celik T., et al.: Bilirubin levels and their association with carotid intima media thickness and high-sensitivity C-reactive protein in patients with psoriasis vulgaris. Am J Clin Dermatol 2014, $15,137-142$

17. Schwertner H.A., Jackson W.G., Tolan G.: Association of low serum concentration of bilirubin with increased risk of coronary artery disease. Clin Chem 1994, 40, 18-23.

18. Vitek L., Jirsa M., Brodanova M., Kalab M., Marecek Z., Danzig V., et al.: Gilbert syndrome and ischemic heart disease: a protective effect of elevated bilirubin levels. Atherosclerosis 2002, 160, 449-456.

19. Novotny L., Vitek L.: Inverse relationship between serum bilirubin and atherosclerosis in men: a meta-analysis of published studies. Exp Biol Med 2003, 228, 568-571.

20. Nano J., Muka T., Cepeda M., Voortman T., Dhana K., Brahimaj A., et al.: Association of circulating total bilirubin with the metabolic syndrome and type 2 diabetes: a systematic review and meta-analysis of observational evidence. Diabetes Metab 2016, 42, 389-397.

21. Andersson C., Weeke P., Fosbol E.L., Brendorp B., Kober L., Coutinho W., et al.: Scout Executive Steering Committee; Scout Investigators: Acute effect of weight loss on levels of total bilirubin in obese, cardiovascular high-risk patients: an analysis from the lead-in period of the Sibutramine Cardiovascular Outcome trial. Metabolism 2009, 58, 1109-1115.

22. Vitek L., Malikova I., Kvasnicka J., Benakova H., Novotny L.: Relationship between serum bilirubin and markers of inflammation and oxidative stress. J Gastroenterol Hepatol 2007, 22, 235.

23. Wagner K.H, Wallner M., Molzer C., Gazzin S., Bulmer A.C., Tiribelli C., et al.: Looking to the horizon: the role of bilirubin in the development and prevention of age-related chronic diseases. Clin Sci 2015, 129, 1-25.

Received: 2.08 .2017

Accepted: 30.09.2017

Otrzymano: 2.08 .2017 r.

Zaakceptowano: 30.09.2017 r.

How to cite this article

Oszukowska M., Kręgiel M., Kaczmarek B., Kaszuba A.: Parameters of liver function in patients with psoriasis vulgaris. Dermatol Rev/Przegl Dermatol 2017, 104, 529-543. DOI: https:/ /doi.org/10.5114/dr.2017.71218. 